\title{
HPV-based Tests for Cervical Cancer Screening and Management of Cervical Disease
}

\author{
Patricia Luhn • Nicolas Wentzensen
}

Published online: 9 March 2013

(C) Springer Science+Business Media New York (outside the USA) 2013

\begin{abstract}
Current cervical cancer screening programs are changing due to the development of tests that detect the presence of human papillomavirus (HPV), the cause of cervical cancer. These tests are more sensitive than cytology-based methods for detecting cervical precancer and a negative test offers long-term assurance that cervical cancer will not develop and therefore longer screening intervals can be achieved. In screening programs, HPV-based tests have been approved to triage women with equivocal cytology results and as a primary testing method in conjunction with cytology. HPV-based tests also have a role in determining risk of recurrence after treatment for cervical precancer as well as in surveillance for vaccine-related changes in HPV genotype prevalence.
\end{abstract}

Keywords HPV · Cervical Cancer · Screening ·

Cervical Precancer $\cdot$ Detection of HPV $\cdot$ Prevention .

Screening Programs

\section{Introduction}

Since the implementation of cytology-based screening programs, or Pap tests, several decades ago, the incidence and mortality of cervical cancer has been declining in developed countries, such as the United States [1]. However, the identification of human papillomaviruses (HPV) as the necessary cause of cervical cancer has changed the paradigm of

P. Luhn $\cdot$ N. Wentzensen $(\bowtie)$

Hormonal and Reproductive Epidemiology Branch, Division of Cancer Epidemiology and Genetics, National Cancer Institute, 6120 Executive Blvd, Suite 550/Room 5024,

Rockville, MD 20892, USA

e-mail: wentzenn@mail.nih.gov

P. Luhn

e-mail: luhnpa@mail.nih.gov

P. Luhn

Cancer Prevention Fellowship Program, Division of Cancer

Prevention, National Cancer Institute, Rockville, MD, USA cervical cancer prevention. For primary prevention, two vaccines that protect against infection by two carcinogenic HPV types (HPV16 and 18) have been approved for use by the Food and Drug Administration (FDA). For secondary prevention, HPV-based tests can identify women at risk for cervical cancer and its precursors and are being incorporated into current screening programs.

Although more than 100 HPV types have been identified to date, only approximately a dozen have been classified as carcinogenic (Group 1) by the International Agency for the Research on Cancer (IARC) [2]. These types include HPV16, 18, 31, 33, 35, 39, 45, 51, 52, 56, 58, and 59. HPV68 is considered probably carcinogenic (Group 2A) and an additional $12 \mathrm{HPV}$ types are classified as possibly carcinogenic (Group 2B; includes HPV26, 30, 34, 53, 66, 67, 69, 70, 73, 82, 85, and 97). Other HPV types are considered low-risk (LR) and are not related to cancer; however, HPV6 and 11 are associated with $\sim 90 \%$ of genital warts.

In recent years, a variety of tests have been developed to detect the presence of HPV in cervical samples. These tests are more sensitive than cytology-based methods for identifying women with high-grade cervical disease and have several roles in current and future cervical cancer prevention programs that will be discussed in this review (Figure 1).

\section{Natural History of HPV Infections and Cervical Carcinogenesis}

Most sexually active women are infected with HPV at least once in their lifetime; however, because most of these women clear the infection, cervical precancers and cancers rarely develop. Infections with multiple HPV genotypes are common, especially among young women [3]. Approximately half of incident infections are undetectable within a year and more than $90 \%$ are undetectable after 3 years [4]. The rate of clearance is highest in the first few months following an 


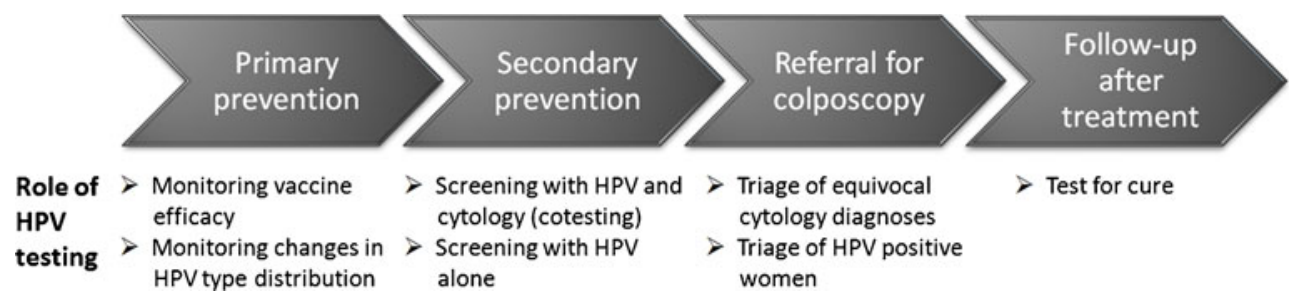

Fig. 1 The roles for HPV testing in cervical cancer prevention. In the primary prevention of cervical cancer, HPV tests are used to monitor vaccine efficacy and changes in genotype prevalence in vaccinated populations. In secondary prevention, HPV tests are used alone or in

infection and diminishes over time [5]. Although persistent infections are uncommon, they carry the highest risk of progressing to cancer. Data from large cohort studies have demonstrated that incident infections at older age are not associated with higher risk of persistence or progression compared with incident infections that occur at younger ages $[4,6]$.

The prevalence of HPV infections peak a few years after the onset of sexual activity and continue to decrease over time $[7,8]$. In the United States, this corresponds to the highest prevalence of HPV infections in the early 20 s. If the infection persists, cervical precancer (cervical intraepithelial neoplasia grade 3 (CIN3)) develops during the next decade, with peak incidence of CIN3 occurring in the mid-20s to 30s. Finally, if left untreated, CIN3 can become invasive carcinoma. This transition takes several decades with the average age of cervical cancer diagnosis in the mid- to late40 s. These progression timelines are similar across populations but may shift based on the average of age at sexual debut. In few places, mainly Africa and Asia, different prevalence age curves have been observed, characterized by high HPV prevalence in older women compared with other places $[9,10]$. The reasons for the different patterns of HPV prevalence in these populations are unknown.

Numerous studies of the prevalence of HPV types across the world have identified HPV16 as the most prevalent type in cervical cancers [11]. A cohort study from Costa Rica showed that among women with persistent infection, HPV16 was more likely to progress compared to other types [8]. The second most common HPV type in cancers worldwide is HPV18; this type is found in a higher proportion of adenocarcinomas compared to squamous cancers. Other carcinogenic types have a lower prevalence but still contribute to the overall cervical cancer burden, albeit to lesser degrees.

\section{Assays to Detect HPV}

Numerous HPV-based assays are commercially available; a summary of widely available tests is shown in Table 1 . Importantly, not all of these tests have been clinically validated, and only a minority have been approved by the FDA. conjunction with cytology for screening. HPV tests also are used to determine who is referred to colposcopy by triaging equivocal cytology diagnoses or HPV-positive women. Finally, HPV tests are important to evaluate risk of recurrence after treatment for cervical precancer

Some assays test for the presence of a pool of carcinogenic HPV types, whereas others provide information on individual genotypes.

\section{HPV DNA Assays}

HPV DNA assays can be divided into the following subgroups: 1) assays that test for the presence of carcinogenic HPV types without providing individual genotyping information; 2) assays that provide genotyping information for few important carcinogenic HPV types, mostly HPV16 and HPV18 (either alone or in conjunction with a test for the presence of carcinogenic HPV); and 3) assays for genotyping a large number of HPV types simultaneously. Because there is currently no clinical benefit of individual genotyping beyond the most important carcinogenic types HPV16 and HPV18, only the first two types of tests are used in screening programs. Tests providing extended genotyping information are primarily used in research or surveillance studies.

The most commonly used HPV DNA assay worldwide is the Hybrid Capture 2 (HC2) HPV DNA Test (QIAGEN), which is a hybridization-based assay that detects 13 carcinogenic HPV types and HPV66; however, cross-reaction with noncarcinogenic HPV types has been described [12]. HC2 was approved in 1999 by the FDA for the triage of women with atypical squamous cells of undetermined significance (ASC-US) cytology to determine which women should be referred to colposcopy and in 2003 for primary screening in conjunction with cytology. Many cohort, cross-sectional, and randomized controlled trials have evaluated $\mathrm{HC} 2$ for the detection of cervical precancer and have been summarized in several meta-analyses [13•, 14-18]. The most recent metaanalysis describing the cross-sectional accuracy of $\mathrm{HC} 2$ report an overall sensitivity of $90 \%$ for the detection of CIN $2+$ and $95 \%$ for $\mathrm{CIN} 3+$, with significant heterogeneity in the estimates from developing countries, but not in industrialized countries and China [13•]. The heterogeneity observed in studies from developing countries may be due to limitations in colposcopy performance and histology verification [14]. The corresponding specificity of $\mathrm{HC} 2$ for the detection of $\mathrm{CIN} 2+$ was reported as $88 \%$ [13•]. Another widely evaluated 
Table 1 Commercially available HPV-based tests

\begin{tabular}{|c|c|c|c|}
\hline Test type and name & Manufacturer & Target molecule & Target HPV genotypes \\
\hline \multicolumn{4}{|l|}{ HPV DNA tests } \\
\hline \multicolumn{4}{|l|}{ HR-HPV DNA assays } \\
\hline Amplicor & Roche & $\mathrm{L} 1$ & 13 carcinogenic \\
\hline CareHPV & QIAGEN & Full Genome & 13 carcinogenic and HPV66 \\
\hline 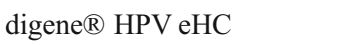 & QIAGEN & Full Genome & 13 carcinogenic, HPV66 and 82 \\
\hline EIA kit HPV GP HR & Diassay & L1 & 13 carcinogenic and HPV66 \\
\hline Hybrid Capture ${ }^{\circledR} 2(\mathrm{HC} 2)^{\mathrm{a}}$ & QIAGEN & Full Genome & 13 carcinogenic and HPV66 \\
\hline INFINITI® HPV-HR QUAD & AutoGenomics & E1 & 13 carcinogenic and HPV66 \\
\hline \multicolumn{4}{|l|}{ HR-HPV assays with genotyping } \\
\hline \multicolumn{4}{|l|}{ Concurrent genotyping } \\
\hline $\operatorname{COBAS} ® 4800^{\mathrm{a}}$ & Roche & L1 & $\begin{array}{l}13 \text { carcinogenic and HPV66; genotyping } \\
\text { for HPV } 16 \text { and } 18\end{array}$ \\
\hline RT HPV & Abbott & L1 & $\begin{array}{l}13 \text { carcinogenic and HPV66; genotyping } \\
\text { for HPV16 and } 18\end{array}$ \\
\hline \multicolumn{4}{|l|}{ Reflex genotyping } \\
\hline Cervista $\AA^{a}$ & Hologic & L1 & $\begin{array}{l}13 \text { carcinogenic and HPV66; genotyping } \\
\text { for HPV16 and } 18\end{array}$ \\
\hline digene ${ }^{\circledR}$ HPV eHC 16 18/45 & QIAGEN & Full Genome & $\begin{array}{l}13 \text { carcinogenic, HPV } 66 \text { and 82; genotyping } \\
\text { for HPV16, } 18 \text { and } 45\end{array}$ \\
\hline \multicolumn{4}{|l|}{ Full genotyping assays } \\
\hline Clart ${ }^{\circledR}$ & Genomica & $\mathrm{L} 1$ & 13 carcinogenic and 22 non-carcinogenic \\
\hline INFINITITM genotyping & AutoGenomics & $\mathrm{L} 1$ & 13 carcinogenic and 12 non-carcinogenic \\
\hline InnoLiPA & Innogenetics & L1 & 13 carcinogenic and 15 non-carcinogenic \\
\hline Linear Array ${ }^{\circledR}$ & Roche & $\mathrm{L} 1$ & 13 carcinogenic and 24 non-carcinogenic \\
\hline Multiplex HPV genotyping & Multimetrix & $\mathrm{L} 1$ & 13 carcinogenic and 11 non-carcinogenic \\
\hline PapilloCheck & Greiner Bio-One & E1 & 13 carcinogenic and 11 non-carcinogenic \\
\hline \multicolumn{4}{|l|}{ HPV RNA tests } \\
\hline APTIMA $\AA^{a}$ & GenProbe & E6/E7 mRNA & 13 carcinogenic and HPV66 \\
\hline NucliSens EasyQ & Biomerieux & E6/E7 mRNA & HPV16, 18, 31, 33, and 45 \\
\hline OncoTect & incellDx & E6/E7 mRNA & 13 carcinogenic \\
\hline PreTect Proofer & Norchip & E6/E7 mRNA & HPV16, 18, 31, 33, and 45 \\
\hline \multicolumn{4}{|l|}{ HPV protein tests } \\
\hline Cytoactiv & Cytoimmun Diagnostics & $\mathrm{L} 1$ & All known HPV types \\
\hline OncoE6 & Arbor Vita & E6 & HPV16, 18 and 45 \\
\hline
\end{tabular}

$H P V$ human papillomavirus; 13 carcinogenic HPV types include HPV68; ${ }^{a}$ FDA-approved tests

HPV DNA test is the GP5+/6+-EIA assay, which is PCRbased, using consensus primers to detect the presence of 13 carcinogenic HPV types and HPV66. The cutoff for positivity for this assay was chosen to provide similar sensitivity and specificity to HC2. Based on the extensive evaluation of these two assays in cervical cancer prevention, minimal criteria for analytic and clinical evaluation of HPV assays have been proposed [18]. According to the recommendations, newly developed assays should reach at least $90 \%$ of the sensitivity and $98 \%$ of the specificity of HC2 or EIA to be considered for use in cervical cancer screening programs.

The careHPV Test (QIAGEN) is a hybridization assay based on $\mathrm{HC} 2$ that is low cost and does not require extensive training or complex laboratory equipment to run, making it an attractive testing method for HPV in rural or lowresource settings. Furthermore, results from this test can be obtained in a short time (approximately 2 hours), allowing for the potential to treat HPV positive women in the same visit, also known as "screen and treat." This assay was validated in a cross-sectional study from rural China that showed a sensitivity of $90 \%$ and specificity of $84 \%$ for the detection of CIN2+ [19].

A subset of HPV assays also provide genotyping information and can be divided into two subgroups: 1) concurrent genotyping assays, i.e., genotyping data is obtained at the same time as the qualitative result; and 2) reflex 
genotyping assays, which provide genotyping data only if a sample is positive for the qualitative test. The two most common tests in this category are the Cervista HPV 16/18 Test (Hologic), which is a reflex genotyping assay, and the COBAS 4800 HPV Test (Roche), which provides concurrent HPV16/18 genotyping information.

Cervista was approved by the FDA in 2009 for 1) the triage of women with ASC-US cytology and 2) determining the presence of carcinogenic HPV types in conjunction with cytology in women older than age 30 years. In a large multicenter, prospective evaluation of women with ASCUS cytology, the sensitivity and specificity of Cervista for the detection of CIN2+ were $93 \%$ and $44 \%$, respectively [20]. Although the sensitivity increased to $100 \%$ for the detection of $\mathrm{CIN} 3+$, the specificity remained similar at $43 \%$. Furthermore data from a large cross-sectional study in China showed that, compared with HC2, Cervista had similar sensitivity but increased specificity for the detection of CIN3+ (relative specificity $=1.03$ [95\% confidence interval (CI) 1.02-1.04]) [13•, 21].

The COBAS 4800 HPV Test was approved by the FDA in 2011 for the following uses: 1) to triage women older than age 21 years with ASC-US cytology; 2) determine the presence of HPV16 and 18 in women older than age 21 years with ASC-US cytology; 3) in conjunction with cytology for primary screening in women older than age 30 years; and 4) determining the presence of HPV16 and 18 in women older than age 30 years. The clinical validation of the COBAS was done through the ATHENA (Addressing THE Need for Advanced HPV Diagnostics) trial and a large European study, both of which focused on the triage of women with ASC-US cytology [22•, 23-25]. These studies showed that, compared with cytology, COBAS was more sensitive (relative sensitivity $=1.77[1.55-1.89]$ ) and just as specific (relative specificity $=0.97[0.97-0.97])$ for the detection of CIN2+ [13•]. Furthermore, the performance of COBAS is similar to that of $\mathrm{HC} 2$ (relative sensitivity and specificity of 0.98 and 1.00 , respectively) [13•].

\section{HPV RNA Assays}

Of the proteins expressed during the life cycle of an HPV infection, the E6 and E7 proteins are the most critical for the development of cancer; overexpression of these proteins leads to the inactivation of $\mathrm{p} 53$ and retinoblastoma, resulting in malignant transformation [26]. Because expression of these proteins is required for carcinogenesis, they make for potentially useful biomarkers of infections that are likely to be associated with cervical cancer or precancer. Furthermore, because E6 and E7 are expressed at higher levels in transforming infections compared with transient infections that will clear spontaneously, determining E6/E7 expression may provide a way to identify clinically relevant HPV infections. Two tests are available to detect mRNA levels of E6/E7: the APTIMA (GenProbe) and the PreTect HPVproofer (Norchip).

The APTIMA HPV Assay detects E6/E7 mRNA from 14 HPV genotypes (13 carcinogenic and HPV66) but does not distinguish between the types. In 2011 the FDA approved the APTIMA for: 1) the triage of women older than age 21 years with ASC-US cytology; and 2) screening of women 30 years of age and older in conjunction with cytology. Several studies have compared the APTIMA to HC2 and cytology-based tests for both primary cervical cancer screening as well as triage of ASC-US or LSIL [27-34]. Results from these studies have been summarized in a number of meta-analyses [13•, 35, 36], each of which suggest that APTIMA has an increased sensitivity, but similar specificity to that of cytology for the detection of CIN2+. Compared with HC2, APTIMA has similar sensitivity but increased specificity for both the triage of ASC-US (relative sensitivity $=1.19[1.08-1.31]$ ) or LSIL (relative sensitivity= 1.37 [0.22-1.54]) as well as in primary screening for CIN2+ or CIN3 + (relative specificity $=1.07$ [1.05-1.08]) [13•].

The PreTect HPV-proofer assay only detects E6/E7 mRNA from five carcinogenic HPV types (HPV16, 18, 31,33 , and 45) and has not been approved by the FDA for use in cervical cancer screening. However, many studies have evaluated the assay for triage of women with ASCUS or LSIL [31, 37-40]. A recent meta-analysis showed that compared with $\mathrm{HC} 2$, the PreTect HPV-proofer assay has a significantly lower sensitivity for the detection of CIN2+ in the triage of women with ASC-US or LSIL (relative sensitivity $=0.79 ; 95 \%$ CI $0.71-0.88)$ and 0.75 (95\% CI $0.67-0.84)$, respectively [13•]. This lower sensitivity has been, in part, attributed to the fact that the assay only detects a small subset of carcinogenic HPV types [41, 42]. In contrast, the PreTect HPV-proofer assay has a much higher specificity compared to $\mathrm{HC} 2$ for the triage of ASC-US (relative specificity $=1.76[1.55-1.99]$ ) and LSIL (relative specificity $=2.79[2.1-3.71])[13 \bullet]$.

\section{HPV Protein Assays}

In addition to tests for E6/E7 mRNA, assays are available to detect protein levels in cervical specimens. A pilot study for a lateral flow assay to detect E6 expression (OncoE6, Arbor Vita Corporation) showed that expression of E6 from HPV16, 18, and/or 45 may be more specific for the detection of CIN3 + compared with HPV-DNA tests [43]. Clinical validation of this assay is ongoing in a population-based study in Shanxi, China, and preliminary results suggest that the OncoE6 has better specificity than HC2 (98.9\% vs. $86.8 \%$, respectively) but lower sensitivity (67.3\% vs. $98 \%$, respectively) for the detection of CIN3+ [44]. Given the increased specificity, the assay may be a useful tool in 
the triage of HPV-positive women. In addition, due to the limited laboratory equipment needed for the assay, it may have applications in low-resource settings.

Loss of the expression of L1, a capsid protein also has been suggested as a marker of progressive lesions [45, 46], and although a test is commercially available to detect the presence of L1 from a number of HPV types (Cytoactiv, Cytoimmun Diagnostics), the clinical utility of this test remains to be determined.

\section{Evidence for HPV Testing}

\section{Triage of Abnormal Cytology}

The first use of HPV testing was in the triage of ASC-US cytology to determine which women should be referred to colposcopy and in 1999, the FDA approved HC2 for this application. A recent meta-analysis of the accuracy of $\mathrm{HC} 2$ reported an overall sensitivity of $90 \%$ and specificity of $58 \%$ for the detection of CIN2+ among women with ASCUS [13•]. The overall sensitivity and specificity for CIN3+ was $94 \%$ and $52 \%$, respectively, in the same population of women. In the triage of women with LSIL, HC2 had similarly high sensitivity for CIN $2+$ or CIN $3+(95 \%$ and $96 \%$, respectively) but lower specificity ( $28 \%$ and $24 \%$, respectively). Compared with HC2, other HPV-based tests have similar sensitivity and, with the exception of a few tests, similar specificity for the detection of CIN2+ among women with ASC-US or LSIL [13•]. Significantly increased specificity, compared with $\mathrm{HC} 2$, was seen for APTIMA, Cervista and Papillocheck in the triage of ASC-US and APTIMA and PreTect HPV-Proofer for the triage of women with LSIL [13•].

\section{Primary Screening}

As previously discussed, results from a large number of cross-sectional studies have shown a high sensitivity of HPV-based tests for the detection of cervical cancer and precancer. This has led to a number of randomized, controlled trials worldwide comparing HPV DNA testing (predominately $\mathrm{HC} 2$ ) with cytology for the detection, and prevention, of cervical cancer and precancer $[47-50,51 \bullet$, $52 \bullet, 53,54,55 \cdot \bullet$. In the first round of screening, which would predominately detect prevalent disease, these studies consistently show that HPV testing has better sensitivity for both CIN2+ and CIN $3+[13 \bullet]$. Of the published trials, four have reported data from the second round of screening [47, $50,51 \bullet \bullet, 52 \bullet \cdot]$. Overall, these results show a decrease in the detection of CIN3+ (Detection Rate Ratio $(D R R)=0.43$ $[0.33-0.56])$ and cancer $(\mathrm{DRR}=0.13[0.04-0.44])$ in the HPV screening arm compared with the cytology arm [13•].
The screening trial conducted in India did not involve multiple visits but did follow participants passively through their cancer registry [55••]. In the HPV screening arm, which was a "screen and treat" modality, a decrease in the incidence of advanced stage (stage II+) cervical cancer (hazard ratio $(\mathrm{HR})=0.47[0.35-0.63]$ ) was observed that was not seen in either the visual inspection or cytology arm. Furthermore, HPV DNA screening led to a decrease in mortality from cervical cancer $(\mathrm{HR}=0.52[0.33-0.83])$. This suggests that even a once-in-a-lifetime screen with HPV can help to reduce the burden of cervical cancer in areas where repeat visits are more difficult to sustain.

The vast majority of studies evaluating HPV tests as a primary screening tool for cervical cancer have used $\mathrm{HC} 2$ or EIA, and thus data on other HPV-based tests for uses outside of triage are limited. In addition, these studies have focused on physician-collected samples. Results from the Netherlands suggest that HPV test results (using GP5+/6+ EIA) from self-collected samples are similar to those from physician-collected samples, suggesting self-collected samples may provide an alternative specimen for HPV testing [56]. This could have important implications for screening in rural or low-resource settings.

\section{Triage of HPV-Positive Women Using Genotyping}

Given the limited specificity of HPV assays for use in large population-based screening programs, a secondary triage test is needed to identify clinically relevant HPV infections. The main evidence for using HPV genotyping as a triage for HPV-positive women comes from the ATHENA trial where different triage options for HPV positive were compared, including genotyping and cytology [22•]. Although limited at this time, these data suggest that genotyping may offer better risk stratification for HPV-positive women than cytology.

Currently, most of the genotyping assays that are available provide information only for HPV16 and 18. The benefit of genotyping for other HR-HPV types is still somewhat unclear. Evidence to date from U.S. studies suggests that it is not likely to be clinically useful $[25,57,58]$; however, reports from a Danish cohort study suggest that HPV 31 and 33 may have similar absolute risks for progressing to cervical cancer as those for HPV18 [59-61].

\section{Follow-Up After Treatment}

Typical treatment for cervical precancer is loop electrosurgical excision procedure (LEEP) of the transformation zone, often leading to the causal HPV type being undetectable in cervical specimens after treatment. Although cytologybased methods have historically been used to determine if a woman has residual or recurrent disease, HPV testing may 
provide a better way to monitor risk of recurrence following treatment. Women who are HPV-positive after LEEP are at increased risk of recurrent disease, whereas a negative HPV test is highly predictive of curative treatment $[62,63]$. A recent meta-analysis of the test performance of HPV-based tests following treatment for cervical precancer showed that, compared with cytology, HPV DNA tests have a significantly higher sensitivity for the detection of recurrent CIN2+ (72\% vs. $93 \%$, respectively) without a considerable difference in specificity ( $84 \%$ vs. $81 \%$, respectively) [13•]. Furthermore, combining cytology and HPV testing did not lead to improved sensitivity but decreased the specificity. Therefore, HPV testing may be a viable option to replace cytology-based methods for this clinical application.

\section{Current Recommendations for the Use of HPV Testing in Cervical Cancer Screening Programs}

In March 2012, the United States Preventative Services Task Force (USPSTF) and a multidisciplinary partnership between the American Cancer Society, American Society for Colposcopy and Cervical Pathology and the American Society for Clinical Pathology (ACS/ASCCP/ASCP) published revised cervical cancer screening guidelines [64, 65]. Recommendations from both groups are very similar and are summarized in Table 2. Both groups do not recommend screening women younger than age 21 years. From age 21-29 years, women should be screened only with Pap testing every 3 years. Beginning at the age 30 years until 65 years, women can either continue to receive Pap tests without HPV testing every 3 years or can receive a Pap test in conjunction with an HPV test every 5 years (the preferred option according to the ACS/ASCCP/ASCP screening guidelines). Screening should not continue after age 65 years with sufficient prior negative screening results or after a hysterectomy. Because the HPV vaccine does not protect against infection by all carcinogenic HPV types, because women may have been vaccinated after exposure to HPV, and because coverage is currently low in the United States, women who have been vaccinated are recommended to follow the same guidelines as women in their age group who have not been vaccinated.

\section{The Future of HPV Testing in Cervical Cancer Prevention}

\section{Co-Testing vs. HPV Alone}

Evidence from large trials and observational studies suggest that there is limited clinical benefit of adding cytology to HPV testing in primary cervical cancer screening. Pooled analyses of data from the randomized, controlled trials that included a co-testing arm (HPV testing and cytology) showed that the addition of cytology did not significantly increase the sensitivity for detecting either CIN2+ or CIN3+ over that of HPV testing alone [13•]. Consequently, a negative HPV test predicts a very low risk of developing into cervical precancer over the next years, similar to the risk in women with a negative co-test $[66,67 \bullet \bullet]$. Accordingly and in contrast to the United States, the Netherlands have implemented HPV testing as a primary test, using cytology as a triage test for HPV-positive women [68].

\section{Triage of HPV-Positive Women}

Currently, two options have been recommended for the triage of HPV-positive women: cytology and HPV genotyping. Other markers that have been studied and show promise for potential triage tests include p16 cytology [69] and DNA methylation (viral [70•, 71-73] and host [74, 75]). Many other markers have been proposed as specific markers for cervical precancer, but clinical data are very limited [76]. Future studies are needed to compare HPV genotyping, cytology, and other triage options to evaluate which tests are clinically useful.

Table 2 Current recommendations for the use of HPV tests in cervical cancer screening programs

\begin{tabular}{lll}
\hline Age group & ACS/ASCCP/ASCP guidelines & USPSTF guidelines \\
\hline$<21$ years & No screening & Not recommended (Grade D) \\
$21-29$ years & Pap test every 3 years; no HPV testing & Pap test every 3 years; no HPV testing (Grade A; Grade D) \\
30-65 years & Pap test with HPV testing every 5 years (preferred) OR & Pap test with HPV testing every 5 years OR Pap test every \\
& Pap test every 3 years; no HPV testing (acceptable) & 3 years; no HPV testing (Grade A) \\
$65+$ years & No screening following adequate prior & Not recommended with adequate negative screening (Grade D) \\
After hysterectomy & No screening & Not recommended (Grade D) \\
Vaccinated women & Same as unvaccinated women & No recommendation offered \\
\hline
\end{tabular}

$H P V$ human papillomavirus; ACS American Cancer Society; ASCCP American Society for Colposcopy and Cervical Pathology; ASCP American Society for Clinical Pathology; USPSTF United States Preventative Services Task Force 
HPV Testing in Vaccinated Populations

In 2006 and 2009, the FDA approved the use of two vaccines that protect against infection by four (Gardasil, Merk \& Co., Inc.) or two (Cervarix, GlaxoSmithKline) HPV types. The bivalent vaccine protects against infection by HPV16 and HPV18, whereas the quadrivalent vaccine also includes HPV6 and HPV11, which cause $90 \%$ of genital warts. Vaccination has been proven to be effective against infection by the types included in the vaccine [77]. There is some evidence of cross-protection against types not included in the vaccine; however, the extent of this protection is currently unclear and may differ between the vaccine types [78]. This is particularly important, because although HPV16 and HPV18 account for a large fraction (70\%) of all cervical cancer cases, there remain many cancers caused by other types. Current recommendations for cervical cancer screening are not different for vaccinated and unvaccinated women; however, this could change in the future. Accumulating data suggest that HPV16-related cervical precancer and cancer occurs at younger ages than non-HPV16-related disease [79-81]. As vaccination becomes more common and HPV16 prevalence decreases in the population, it may become possible to begin cervical cancer screening at an older age than is currently recommended. Continued research is needed to evaluate the risks and benefits of changing the screening age of women once they are vaccinated.

HPV-based tests will be important to evaluate the efficacy of vaccination programs. Histology and cytology-based outcomes are subject to interobserver variability and can take decades to develop if CIN3 or cancer are considered as outcomes. Using HPV tests to monitor the prevalence of vaccine-related types offers a surrogate measure of the efficacy of a vaccine program. Furthermore, a decrease in the prevalence of HPV16 and 18 should be noticeable much earlier than disease endpoints. Registries, such as the New Mexico Pap Registry, which was developed as an effort to monitor the impact of HPV vaccine uptake and changes in cervical cancer screening behaviors over time, will be vitally important for monitoring vaccine efficacy and potential type-replacement as vaccination coverage increases [82].

\section{Conclusions}

HPV-based tests offer a more sensitive way to identify women with high-grade cervical disease compared with cytology-based methods. This, coupled with the assurance that a negative test offers, make HPV tests an attractive method for cervical cancer screening. The use of HPV assays as a primary screening method requires the use of a triage test to identify women with clinically relevant infections. In the future, HPV testing will continue to be important for surveillance and monitoring vaccine efficacy.

Conflict of Interest Nicolas Wentzensen declares that he has no conflict of interest.

Patricia Luhn declares that she has no conflict of interest.

\section{References}

Paper of particular interest, published recently, have been highlighted as:

- Of importance,

•- Of major importance

1. Saslow D, Runowicz CD, Solomon D, Moscicki AB, Smith RA, Eyre HJ, et al. American Cancer Society guideline for the early detection of cervical neoplasia and cancer. CA Cancer J Clin. 2002;52:342-62.

2. Bouvard V, Baan R, Straif K, Grosse Y, Secretan B, El Ghissassi F, et al. A review of human carcinogens-Part B: biological agents. Lancet Oncol. 2009;10:321-2.

3. Wentzensen N, Schiffman M, Dunn T, Zuna RE, Gold MA, Allen RA, et al. Multiple human papillomavirus genotype infections in cervical cancer progression in the study to understand cervical cancer early endpoints and determinants. Int J Canc. 2009;125:2151-58.

4. Rodriguez AC, Schiffman M, Herrero R, Wacholder S, Hildesheim A, Castle PE, et al. Rapid clearance of human papillomavirus and implications for clinical focus on persistent infections. J Natl Cancer Inst. 2008;100:513-7.

5. Plummer M, Schiffman M, Castle PE, Maucort-Boulch D, Wheeler CM. A 2-year prospective study of human papillomavirus persistence among women with a cytological diagnosis of atypical squamous cells of undetermined significance or low-grade squamous intraepithelial lesion. J Infect Dis. 2007;195:1582-9.

6. Maucort-Boulch D, Plummer M, Castle PE, Demuth F, Safaeian M, Wheeler CM, et al. Predictors of human papillomavirus persistence among women with equivocal or mildly abnormal cytology. Int J Cancer. 2010;126:684-91.

7. Schiffman M, Wentzensen N, Wacholder S, Kinney W, Gage JC, Castle PE. Human Papillomavirus Testing in the Prevention of Cervical Cancer. J Natl Canc Inst. 2011;103:368-83.

8. Castle PE, Schiffman M, Herrero R, Hildesheim A, Rodriguez AC, Bratti MC, et al. A prospective study of age trends in cervical human papillomavirus acquisition and persistence in Guanacaste, Costa Rica. J Infect Dis. 2005;191:1808-16.

9. Gage JC, Ajenifuja KO, Wentzensen NA, Adepiti AC, Eklund C, Reilly M, et al. The age-specific prevalence of human papillomavirus and risk of cytologic abnormalities in rural Nigeria: implications for screen-and-treat strategies. Int J Cancer. 2012;130:2111-7.

10. Franceschi S, Herrero R, Clifford GM, Snijders PJ, Arslan A, Anh PT, et al. Variations in the age-specific curves of human papillomavirus prevalence in women worldwide. Int $\mathrm{J}$ Cancer. 2006;119:2677-84.

11. Li N, Franceschi S, Howell-Jones R, Snijders PJ, Clifford GM. Human papillomavirus type distribution in 30,848 invasive cervical 
cancers worldwide: Variation by geographical region, histological type and year of publication. Int J Cancer. 2011;128:927-35.

12. Castle PE, Schiffman M, Burk RD, Wacholder S, Hildesheim A, Herrero R, et al. Restricted cross-reactivity of hybrid capture 2 with nononcogenic human papillomavirus types. Cancer Epidemiol Biomarkers Prev. 2002;11:1394-9.

13. - Arbyn M, Ronco G, Anttila A, Meijer CJ, Poljak M, Ogilvie G, et al. Evidence regarding human papillomavirus testing in secondary prevention of cervical cancer. Vaccine. 2012;30 Suppl 5:F88-99. This meta-analysis summarizes currently available data for the evidence for the use of HPV tests in different clinical applications.

14. Arbyn M, Sasieni P, Meijer CJ, Clavel C, Koliopoulos G, Dillner J. Chapter 9: Clinical applications of HPV testing: a summary of meta-analyses. Vaccine. 2006;24 Suppl 3:S3/78-89.

15. Cox JT. History of the use of HPV testing in cervical screening and in the management of abnormal cervical screening results. J Clin Virol. 2009;45 Suppl 1:S3-S12.

16. Cuzick J, Arbyn M, Sankaranarayanan R, Tsu V, Ronco G, Mayrand $\mathrm{MH}$, et al. Overview of human papillomavirus-based and other novel options for cervical cancer screening in developed and developing countries. Vaccine. 2008;26 Suppl 10: K29-41

17. Cuzick J, Clavel C, Petry KU, Meijer CJ, Hoyer H, Ratnam S, et al. Overview of the European and North American studies on HPV testing in primary cervical cancer screening. Int $\mathrm{J}$ Cancer. 2006;119:1095-101.

18. Meijer CJ, Berkhof J, Castle PE, Hesselink AT, Franco EL, Ronco $\mathrm{G}$, et al. Guidelines for human papillomavirus DNA test requirements for primary cervical cancer screening in women 30 years and older. Int J Cancer. 2009;124:516-20.

19. Qiao YL, Sellors JW, Eder PS, Bao YP, Lim JM, Zhao FH, et al. A new HPV-DNA test for cervical-cancer screening in developing regions: a cross-sectional study of clinical accuracy in rural China. Lancet Oncol. 2008;9:929-36.

20. Einstein MH, Martens MG, Garcia FA, Ferris DG, Mitchell AL, Day SP, et al. Clinical validation of the Cervista HPV HR and 16/ 18 genotyping tests for use in women with ASC-US cytology. Gynecol Oncol. 2010;118:116-22.

21. Belinson JL, Wu R, Belinson SE, Qu X, Yang B, Du H, et al. A population-based clinical trial comparing endocervical high-risk HPV testing using hybrid capture 2 and Cervista from the SHENCCAST II Study. Am J Clin Pathol. 2011;135:790-5.

22. - Castle PE, Stoler MH, Wright Jr TC, Sharma A, Wright TL, Behrens CM. Performance of carcinogenic human papillomavirus (HPV) testing and HPV16 or HPV18 genotyping for cervical cancer screening of women aged 25 years and older: a subanalysis of the ATHENA study. Lancet Oncol. 2011;12:880-90. This study reports the clinical utility of using HPV genotyping as a triage test for HPV positive women

23. Heideman DA, Hesselink AT, Berkhof J, van Kemenade F, Melchers WJ, Daalmeijer NF, et al. Clinical validation of the cobas $4800 \mathrm{HPV}$ test for cervical screening purposes. J Clin Microbiol. 2011;49:3983-5.

24. Stoler MH, Wright Jr TC, Sharma A, Apple R, Gutekunst K, Wright TL. High-risk human papillomavirus testing in women with ASC-US cytology: results from the ATHENA HPV study. Am J Clin Pathol. 2011;135:468-75.

25. Wright Jr TC, Stoler MH, Sharma A, Zhang G, Behrens C, Wright TL. Evaluation of HPV-16 and HPV-18 genotyping for the triage of women with high-risk HPV+cytology-negative results. Am J Clin Pathol. 2011;136:578-86.

26. Munger K, Scheffner M, Huibregtse JM, Howley PM. Interactions of HPV E6 and E7 oncoproteins with tumour suppressor gene products. Cancer Surv. 1992;12:197-217.

27. Dockter J, Schroder A, Hill C, Guzenski L, Monsonego J, Giachetti C. Clinical performance of the APTIMA HPV Assay for the detection of high-risk HPV and high-grade cervical lesions. J Clin Virol. 2009;45 Suppl 1:S55-61.

28. Monsonego J, Hudgens MG, Zerat L, Zerat JC, Syrjanen K, Halfon P, et al. Evaluation of oncogenic human papillomavirus RNA and DNA tests with liquid-based cytology in primary cervical cancer screening: the FASE study. Int J Cancer. 2011;129:691-701.

29. Monsonego J, Hudgens MG, Zerat L, Zerat JC, Syrjanen K, Smith JS. Risk assessment and clinical impact of liquid-based cytology, oncogenic human papillomavirus (HPV) DNA and mRNA testing in primary cervical cancer screening (the FASE study). Gynecol Oncol. 2012;125:175-80.

30. Ratnam S, Coutlee F, Fontaine D, Bentley J, Escott N, Ghatage P, et al. Aptima HPV E6/E7 mRNA test is as sensitive as Hybrid Capture 2 Assay but more specific at detecting cervical precancer and cancer. J Clin Microbiol. 2011;49:557-64.

31. Szarewski A, Ambroisine L, Cadman L, Austin J, Ho L, Terry G, et al. Comparison of predictors for high-grade cervical intraepithelial neoplasia in women with abnormal smears. Cancer Epidemiol Biomarkers Prev. 2008;17:3033-42.

32. Wu R, Belinson SE, Du H, Na W, Qu X, Liu Y, et al. Human papillomavirus messenger RNA assay for cervical cancer screening: the Shenzhen Cervical Cancer Screening Trial I. Int J Gynecol Cancer. 2010;20:1411-4.

33. Szarewski A, Mesher D, Cadman L, Austin J, Ashdown-Barr L, Ho L, et al. Comparison of seven tests for high-grade cervical intraepithelial neoplasia in women with abnormal smears: the Predictors 2 study. J Clin Microbiol. 2012;50:1867-73.

34. Clad A, Reuschenbach M, Weinschenk J, Grote R, Rahmsdorf J, Freudenberg N. Performance of the Aptima high-risk human papillomavirus mRNA assay in a referral population in comparison with Hybrid Capture 2 and cytology. J Clin Microbiol. 2011;49:1071-6.

35. Burger EA, Kornor H, Klemp M, Lauvrak V, Kristiansen IS. HPV mRNA tests for the detection of cervical intraepithelial neoplasia: a systematic review. Gynecol Oncol. 2011;120:430-8.

36. Cuschieri K, Wentzensen N. Human papillomavirus mRNA and p16 detection as biomarkers for the improved diagnosis of cervical neoplasia. Cancer Epidemiol Biomarkers Prev. 2008;17:2536-45.

37. Ratnam S, Coutlee F, Fontaine D, Bentley J, Escott N, Ghatage P, et al. Clinical performance of the PreTect HPV-Proofer E6/E7 mRNA assay in comparison with that of the Hybrid Capture 2 test for identification of women at risk of cervical cancer. J Clin Microbiol. 2010;48:2779-85.

38. Benevolo M, Vocaturo A, Caraceni D, French D, Rosini S, Zappacosta R, et al. Sensitivity, specificity, and clinical value of human papillomavirus (HPV) E6/E7 mRNA assay as a triage test for cervical cytology and HPV DNA test. J Clin Microbiol. 2011;49:2643-50.

39. Sorbye SW, Arbyn M, Fismen S, Gutteberg TJ, Mortensen ES Triage of women with low-grade cervical lesions-HPV mRNA testing versus repeat cytology. PLoS One. 2011;6:e24083.

40. Sorbye SW, Arbyn M, Fismen S, Gutteberg TJ, Mortensen ES. HPV E6/E7 mRNA testing is more specific than cytology in postcolposcopy follow-up of women with negative cervical biopsy. PLoS One. 2011;6:e26022.

41. Hovland S, Arbyn M, Lie AK, Ryd W, Borge B, Berle EJ, et al. A comprehensive evaluation of the accuracy of cervical pre-cancer detection methods in a high-risk area in East Congo. Br J Cancer. 2010;102:957-65.

42. Poljak M, Kocjan BJ. Commercially available assays for multiplex detection of alpha human papillomaviruses. Expert Rev Anti Infect Ther. 2010;8:1139-62.

43. Schweizer J, Lu PS, Mahoney CW, Berard-Bergery M, Ho M, Ramasamy V, et al. Feasibility study of a human papillomavirus E6 oncoprotein test for diagnosis of cervical precancer and cancer. J Clin Microbiol. 2010;48:4646-8. 
44. Cuzick J, Bergeron C, von Knebel DM, Gravitt P, Jeronimo J, Lorincz AT, et al. New technologies and procedures for cervical cancer screening. Vaccine. 2012;30 Suppl 5:F107-16.

45. Rauber D, Mehlhorn G, Fasching PA, Beckmann MW, Ackermann S. Prognostic significance of the detection of human papilloma virus L1 protein in smears of mild to moderate cervical intraepithelial lesions. Eur J Obstet Gynecol Reprod Biol. 2008;140:258-62.

46. Griesser H, Sander H, Walczak C, Hilfrich RA. HPV vaccine protein L1 predicts disease outcome of high-risk HPV+early squamous dysplastic lesions. Am J Clin Pathol. 2009;132:840-5.

47. Kitchener HC, Almonte M, Gilham C, Dowie R, Stoykova B, Sargent A, et al. ARTISTIC: a randomised trial of human papillomavirus (HPV) testing in primary cervical screening. Health Technol Assess 2009;13:1-150, iii-iv.

48. Leinonen M, Nieminen P, Kotaniemi-Talonen L, Malila N, Tarkkanen J, Laurila P, et al. Age-specific evaluation of primary human papillomavirus screening vs conventional cytology in a randomized setting. J Natl Cancer Inst. 2009;101:1612-23.

49. Mayrand MH, Duarte-Franco E, Rodrigues I, Walter SD, Hanley J, Ferenczy A, et al. Human papillomavirus DNA versus Papanicolaou screening tests for cervical cancer. N Engl J Med. 2007;357:1579-88.

50. Naucler P, Ryd W, Tornberg S, Strand A, Wadell G, Elfgren K, et al. Human papillomavirus and Papanicolaou tests to screen for cervical cancer. N Engl J Med. 2007;357:1589-97.

51. •• Rijkaart DC, Berkhof J, Rozendaal L, van Kemenade FJ, Bulkmans NW, Heideman DA, et al. Human papillomavirus testing for the detection of high-grade cervical intraepithelial neoplasia and cancer: final results of the POBASCAM randomised controlled trial. Lancet Oncol. 2012;13:78-88. This randomized controlled trial in the Netherlands showed that HPV testing was more sensitive than cytology in the first round of screening and decreased the incidence of precancer and cancer in the second round.

52. • Ronco G, Giorgi-Rossi P, Carozzi F, Confortini M, Dalla Palma P, Del Mistro A, et al. Efficacy of human papillomavirus testing for the detection of invasive cervical cancers and cervical intraepithelial neoplasia: a randomised controlled trial. Lancet Oncol. 2010;11:249-57. This randomized controlled trial conducted in Europe showed that HPV-based screening reduced the incidence of precancer in the second round of screening.

53. Ronco G, Giorgi-Rossi P, Carozzi F, Confortini M, Dalla Palma P, Del Mistro A, et al. Results at recruitment from a randomized controlled trial comparing human papillomavirus testing alone with conventional cytology as the primary cervical cancer screening test. J Natl Cancer Inst. 2008;100:492-501.

54. Ronco G, Giorgi-Rossi P, Carozzi F, Dalla Palma P, Del Mistro A, De Marco L, et al. Human papillomavirus testing and liquid-based cytology in primary screening of women younger than 35 years: results at recruitment for a randomised controlled trial. Lancet Oncol. 2006;7:547-55.

55. • Sankaranarayanan R, Nene BM, Shastri SS, Jayant K, Muwonge $\mathrm{R}$, Budukh AM, et al. HPV screening for cervical cancer in rural India. N Engl J Med. 2009;360:1385-94. This was the first randomized controlled trial comparing HPV testing to cytology, showing that HPV screening was not only more sensitive for detecting precancer but also reduced cervical cancer related mortality.

56. Dijkstra MG, Heideman DA, van Kemenade FJ, Hogewoning KJ, Hesselink AT, Verkuijten MC, et al. Brush-based self-sampling in combination with GP5+/6+-PCR-based hrHPV testing: high concordance with physician-taken cervical scrapes for HPV genotyping and detection of high-grade CIN. J Clin Virol. 2012;54:147-51.

57. Khan MJ, Castle PE, Lorincz AT, Wacholder S, Sherman M, Scott $\mathrm{DR}$, et al. The elevated 10-year risk of cervical precancer and cancer in women with human papillomavirus (HPV) type 16 or 18 and the possible utility of type-specific HPV testing in clinical practice. J Natl Cancer Inst. 2005;97:1072-9.
58. Wright Jr TC, Stoler MH, Behrens CM, Apple R, Derion T, Wright TL. The ATHENA human papillomavirus study: design, methods, and baseline results. Am J Obstet Gynecol. 2012;206:46 e1-46 e11.

59. Berkhof J, Bulkmans NW, Bleeker MC, Bulk S, Snijders PJ, Voorhorst FJ, et al. Human papillomavirus type-specific 18month risk of high-grade cervical intraepithelial neoplasia in women with a normal or borderline/mildly dyskaryotic smear. Cancer Epidemiol Biomarkers Prev. 2006;15:1268-73.

60. • Kjaer SK, Frederiksen K, Munk C, Iftner T. Long-term absolute risk of cervical intraepithelial neoplasia grade 3 or worse following human papillomavirus infection: role of persistence. J Natl Cancer Inst. 2010;102:478-88. This large longitudinal study evaluated the risk of cervical precancer following an HPV infection and showed the higher risk of precancer associated with persistent HPV16 infections.

61. Naucler P, Ryd W, Tornberg S, Strand A, Wadell G, Hansson BG, et al. HPV type-specific risks of high-grade CIN during 4 years of follow-up: a population-based prospective study. $\mathrm{Br} \mathrm{J}$ Cancer. 2007;97:129-32.

62. Kreimer AR, Guido RS, Solomon D, Schiffman M, Wacholder S, Jeronimo $\mathrm{J}$, et al. Human papillomavirus testing following loop electrosurgical excision procedure identifies women at risk for posttreatment cervical intraepithelial neoplasia grade 2 or 3 disease. Cancer Epidemiol Biomarkers Prev. 2006;15:908-14.

63. Kreimer AR, Katki HA, Schiffman M, Wheeler CM, Castle PE. Viral determinants of human papillomavirus persistence following loop electrical excision procedure treatment for cervical intraepithelial neoplasia grade 2 or 3. Cancer Epidemiol Biomarkers Prev. 2007;16:11-6.

64. Saslow D, Solomon D, Lawson HW, Killackey M, Kulasingam SL, Cain J, et al. American Cancer Society, American Society for Colposcopy and Cervical Pathology, and American Society for Clinical Pathology screening guidelines for the prevention and early detection of cervical cancer. CA Cancer J Clin. 2012;62:147-72.

65. Moyer VA. Screening for cervical cancer: U.S. Preventive Services Task Force recommendation statement. Ann Intern Med 2012;156:880-91, W312.

66. Dillner J, Rebolj M, Birembaut P, Petry KU, Szarewski A, Munk $\mathrm{C}$, et al. Long term predictive values of cytology and human papillomavirus testing in cervical cancer screening: joint European cohort study. BMJ. 2008;337:a1754.

67. •• Katki HA, Kinney WK, Fetterman B, Lorey T, Poitras NE, Cheung L, et al. Cervical cancer risk for women undergoing concurrent testing for human papillomavirus and cervical cytology: a population-based study in routine clinical practice. Lancet Oncol. 2011;12:663-72. This analysis from a large health maintenance organization demostrated the low risk of precancer in women testing HPV negative over the next 3-5 years.

68. Rijkaart DC, Berkhof J, van Kemenade FJ, Coupe VM, Rozendaal L, Heideman DA, et al. HPV DNA testing in population-based cervical screening (VUSA-Screen study): results and implications. Br J Cancer. 2012;106:975-81.

69. Carozzi F, Gillio-Tos A, Confortini M, Del Mistro A, Sani C, De Marco L, et al. Risk of high-grade cervical intraepithelial neoplasia during follow-up in HPV-positive women according to baseline p16-INK4A results: a prospective analysis of a nested substudy of the NTCC randomised controlled trial. Lancet Oncol. $2013 ; 14: 168-76$

70. - Wentzensen N, Sun C, Ghosh A, Kinney W, Mirabello L, Wacholder S, et al. Methylation of HPV18, HPV31, and HPV45 genomes and cervical intraepithelial neoplasia grade 3. J Natl Cancer Inst. 2012;104:1738-49. This study showed that methylation of carcinogenic HPV types is associated with cervical precancer.

71. Clarke MA, Wentzensen N, Mirabello L, Ghosh A, Wacholder S, Harari A, et al. Human papillomavirus DNA methylation as a 
potential biomarker for cervical cancer. Cancer Epidemiol Biomarkers Prev. 2012;21:2125-37.

72. Mirabello L, Schiffman M, Ghosh A, Rodriguez AC, Vasiljevic N, Wentzensen N, et al. Elevated methylation of HPV16 DNA is associated with the development of high grade cervical intraepithelial neoplasia. Int J Cancer. 2013;132:1412-22.

73. Mirabello L, Sun C, Ghosh A, Rodriguez AC, Schiffman M, Wentzensen N, et al. Methylation of human papillomavirus type 16 genome and risk of cervical precancer in a Costa Rican population. J Natl Cancer Inst. 2012;104:556-65.

74. Eijsink JJ, Lendvai A, Deregowski V, Klip HG, Verpooten G, Dehaspe L, et al. A four-gene methylation marker panel as triage test in high-risk human papillomavirus positive patients. Int $\mathrm{J}$ Cancer. 2012;130:1861-9.

75. Hesselink AT, Heideman DA, Steenbergen RD, Coupe VM, Overmeer RM, Rijkaart D, et al. Combined promoter methylation analysis of CADM1 and MAL: an objective triage tool for highrisk human papillomavirus DNA-positive women. Clin Cancer Res. 2011;17:2459-65.

76. Sahasrabuddhe VV, Luhn P, Wentzensen N. Human papillomavirus and cervical cancer: biomarkers for improved prevention efforts. Future Microbiol. 2011;6:1083-98.

77. Lu B, Kumar A, Castellsague X, Giuliano AR. Efficacy and safety of prophylactic vaccines against cervical HPV infection and diseases among women: a systematic review \& meta-analysis. BMC Infect Dis. 2011;11:13.

78. Malagon T, Drolet M, Boily MC, Franco EL, Jit M, Brisson J, et al. Cross-protective efficacy of two human papillomavirus vaccines: a systematic review and meta-analysis. Lancet Infect Dis. 2012;12:781-9.

79. Wentzensen N, Walker J, Schiffman M, Yang HP, Zuna RE, Dunn ST, et al. Heterogeneity of high-grade cervical intraepithelial neoplasia related to HPV16: Implications for natural history and management. Int J Cancer. 2013;132:148-54.

80. Porras C, Rodriguez AC, Hildesheim A, Herrero R, Gonzalez P, Wacholder S, et al. Human Papillomavirus Types by Age in Cervical Cancer Precursors: Predominance of Human Papillomavirus 16 in Young Women. Cancer Epidemiology Biomarkers \& Prevention. 2009;18:863-65.

81. Wheeler CM, Hunt WC, Joste NE, Key CR, Quint WG, Castle PE. Human papillomavirus genotype distributions: implications for vaccination and cancer screening in the United States. J Natl Cancer Inst. 2009;101:475-87.

82. Wheeler CM, Hunt WC, Cuzick J, Langsfeld E, Pearse A, Montoya GD, et al. A population-based study of human papillomavirus genotype prevalence in the United States: baseline measures prior to mass human papillomavirus vaccination. Int J Cancer. 2013;132:198-207. 